\title{
EL FIN DEL ESTADO DE BIENESTAR SOCIAL: LAS POLÍTICAS PÚBLICAS EN EL ESTADO NECRONEOLIBERAL
}

\section{Lizbeth Xóchitl PADILLA SANABRIA}

\begin{abstract}
Sumario:
I. Nota introductoria II. El Estado de Bienestar social y su decadencia: El neoliberalismo y las políticas públicas III. El Estado Necroneoliberal: La muerte y la violencia como ejes básicos de las políticas públicas IV. Conclusión V. Bibliografía
\end{abstract}

Resumen. La funcionalidad sistémica de la administración pública global y estatal, así como la materialización de la misma en políticas públicas, debe ser analizada desde aspectos multidisciplinarios, tales como la economía, la política, el derecho, entre otras. Achille Mbembe utiliza como punto de partida a la necropolítica, es decir, el ejercicio del poder a través de la violencia y la muerte; dicho autor retoma la biopolítica de Michel Foucault para fundamentarla. Bajo esa perspectiva, los sujetos sociales, en tanto ciudadanos, son diseñados físicamente y construidos ideológicamente de acuerdo al modo productivo neoliberal actual; sin embargo, el neoliberalismo utiliza a la muerte y a la violencia para producir acumulación incesante de capital.

Palabras clave: necroneliberalismo, biopolítica, necropoder, administración pública.

\begin{abstract}
The functionality sistémica of the public administration global and state, as well as the materialisation of the same in public politics, has to be analysed from appearances multidisciplinarios, such as the economy, the politics, the right, between others. Achille Mbembe uses like starting point to the necropolitica, that is to say, the exercise of the power through the violence and the death; said author restarts the biopolitica of Michel Foucault to base it. Under this perspective, the social subjects, in so many citizens, are designed physically and built ideologicamente of agreement to the productive way neoliberal current; however, the neoliberalism uses to the death and to the violence to produce incessant accumulation of capital.
\end{abstract}

Key Words: necroneoliberalism, biopolitics, necropower, public administración.

\footnotetext{
* Doctora en Derecho por la Universidad Nacional Autónoma de México, Posdoctorado en Derecho y Ciencias Sociales en la Benemérita Universidad Autónoma de Puebla, Investigadora SNI, Profesora de Carrera Asociado "C", Tiempo Completo en la Facultad de Estudios Superiores Acatlán.
} 


\section{Nota introductoria}

La administración pública y la inserción de políticas públicas no funcionan de igual manera en todos los grupos sociales ni en todas la épocas; la llamada paz social depende de la eficacia y eficiencia que el control social logre con la aplicabilidad de ambas.

De lo anterior se puede deducir que la administración pública clasifica las prioridades funcionales del sistema, las cuales se materializan en políticas públicas.

De ahí que siendo el sistema económico el dominante, las políticas públicas y la administración pública, tanto en el ámbito local como en el internacional, se dirigirán a la protección del primero.

En efecto, si los sujetos sociales son el elemento dominante que produce capital a través de su trabajo, entonces la administración pública y las políticas públicas estarán dirigidas hacia su protección; en cambio, si el factor básico de acumulación de capital es la especulación o la desregulación económica a través de la competencia de libre mercado, el recorte al gasto público, la desestatización, así como la inversión extranjera directa, cierto es que nuestros objetos de estudio estarán dirigidos a la protección de la dinámica económica neoliberal.

El problema básico consiste en el papel que juegan los sujetos sociales y en sus alcances de supervivencia en una administración pública con políticas dirigidas a resguardar el capital global.

Al comparar la dirección de las políticas públicas en el Estado de Bienestar Social con la del Estado Neoliberal es factible vislumbrar la funcionalidad-finalidad del papel que juegan la violencia y la muerte en la administración de los estados que actualmente sufren la imposición de la dinámica económica neoliberal. Con base en la metodología de Mbembe y Foucault intentaremos construir, describir, así como revelar la funcionalidad-finalidad en las actuales administraciones neoliberales y en sus políticas públicas en el que llamamos El Estado Necroneoliberal.

\section{El Estado de Bienestar social y su decadencia: El neoliberalismo y las políticas públicas}

Frecuentemente el Estado de Bienestar Social es considerado como un ente abstracto que tiene como fin la protección de los sujetos sociales; sin embargo, éste es un estado planificador cuyo objetivo principal es la conquista de territorios a través de guerras materiales y corporales a efecto de que la población produzca y consuma siempre con una base económica.

Montoro desarrolla tres ejes fundamentales mediante los cuales considera que el Estado de Bienestar Social ha tenido éxito:

Tres importantes razones avalan la tesis transicional y el mantenimiento del Bienestar como valor colectivo: 1) en primer lugar, precisamente por su componente de ideario cultural y valorativo; su gran éxito entre la ciudadanía; su identidad como valor cultural y político. 2) En segundo lugar, porque ha sido capaz de definir sociedades enteras, yendo incluso más allá de la identificación bajo el formato de Estado de Bienestar. Realmente si todo sale bien y se hacen los deberes correctamente, las "sociedades del Estado de Bienestar" de las pasadas décadas se transformarán en "Sociedades del Bienestar", logrando una nueva identidad colectiva en torno a la idea de Bienestar. Se trata de una categoría tan poderosa que podría entenderse paralela a la clásica de "países desarrollados y países en vías de desarrollo". 3) Y, por fin, el tercer gran motivo es que la idea de Bienestar está intimamente asociada a la paz y concordia sociales que vive occidente, hasta el extremo que puede servir de indicador para otros países que buscan su equilibrio interno en los grandes acuerdos ciudadanos. El sentido común indica, 
pues, que la idea de bienestar, redefinida, debe pervivir por el bien de la colectividad. El equilibrio social siempre frágil así lo exige ${ }^{1}$.

Harris nos indica también, con respecto al Estado de Bienestar Social, que: El Estado controla una parte tan grande de la economía que un planificador puede, mediante la manipulación inteligente de las palancas del poder público, dirigir el resto de la economía con firmeza hacia cualquier objetivo que el gobierno elija ${ }^{2}$.

Las políticas globales del Estado de bienestar social tienen como fin evitar que bloques distintos se apoderen de regiones productivas a efecto de impedir cualquier tipo de competencia, ya sea económica, política, jurídica o ideológica. En ese sentido proliferan constructos ideológicos de control, tales como bienestar y democracia, entre otros.

La transición del liberalismo al Estado de Bienestar Social atendió a elementos eminentemente económicos, toda vez que las crisis económicas de los años veintes anunciaron el comienzo de la protección de los sujetos sociales en diversas esferas socio-económicas.

Eugenio Rivera Urrutia nos indica que el Estado de Bienestar Social es producto de un necesario cambio en el sistema económico:

La grave crisis que atravesó el capitalismo desde fines de la década de 1920 y durante la de 1930 generó un ambiente intelectual fuertemente contrario a las políticas del "laissez faire". Los objetivos de asegurar el pleno empleo y reducir las fluctuaciones económicas se pusieron en el centro de la agendas de la política pública. El keynesianismo entregó el fundamento conceptual a una activa política macroeconómica³.

En este sentido el Estado de Bienestar Social protege a los sujetos sociales con el fin de producir más y consumir al mismo tiempo, los sujetos se concentraron en las ciudades para asegurar el consumo. De esta forma se financian programas de desarrollo, así como arquitecturas sustentables para el bienestar social. Pero esa administración territorial concentra a la población para controlarla y a partir de ahí buscar su explotación y controlar la distribución de alimentos, aún y cuando se convierta en un estado autoritario que a su vez regula, institucionaliza y administra la violencia a través de la sumisión y consensos de los sujetos a través de la voluntad generalizada mediante el voto: El sistema democrático y específicamente la votación, aparece como un mecanismo donde cada individuo entrega su opinión sobre la voluntad general ${ }^{4}$.

Como estado planificador, el Estado de Bienestar Social requiere de un control de las masas trabajadoras a través de los sindicatos, salarios y políticas públicas de protección social.

Sin embargo, el Estado de Bienestar Social entra en crisis porque económicamente sus estructuras ya no tienen la capacidad de dar bienestar, en virtud del excesivo gasto público y falta del mismo.

Montoro considera que una de las causas de crisis del Estado de Bienestar Social es el desequilibrio que existe entre los derechos y deberes de los ciudadanos:

\footnotetext{
${ }^{1}$ Montoro Romero, Ricardo (1997), "La Reforma del Estado de Bienestar: Derechos, deberes e igualdad de oportunidades”, Revista Española de Investigaciones Sociológicas, número 79, Julio-septiembre, p. 13.

2 Harris, Nigel (2006), "Globalización y tendencias en la gestión de las Ciudades", Gestión y Política Pública, volumen 15, Número 1, I Semestre, p. 174.

3 Rivera Urrutia, Eugenio (2004), "Teorías de la regulación en la perspectiva de las políticas públicas", Gestión y Política Pública, volumen 13, número 2, II Semestre, pp. 311.

${ }^{4}$ Idem. p. 315.
} 
En la actualidad, el Estado de Bienestar ha provocado un serio desequilibrio, y $<<$ hoy día la conexión entre derechos $y$ deberes se ha roto, y, además, los derechos ya no son iguales en el sentido de que no son los mismos para todos: son mayores para algunos y menores para otros. A nuestro ciudadano que tiene problemas en casa por tener un anciano se le ha hecho entender que él es la víctima, que no tiene deberes como sujeto individual, y que sólo tiene derechos ante alguien (obviamente el Estado) para que le solucione el problema. Esta visión ha generado multitud de situaciones en las que los individuos particulares no tienen responsabilidad ni deberes contraídos ${ }^{5}$.

Y de acuerdo con el cambio global en los ámbitos económico, político y jurídico, en general cultural, el Estado de Bienestar Social cada vez se escinde más de la planificación de políticas públicas domésticas para abrirse a la transnacionalidad económica.

Aún y cuando se pudiera pensar que las políticas públicas deben estar alejadas de la intervención económica, esto no puede ser posible, toda vez que el Estado en una época globalizadora como la nuestra, requiere insertar en su economía capital externo para poder mantenerse vigente. Montero nos indica al respecto:

Efectivamente, la reducción de la política social a la administración social”, implicando exclusivamente a los poderes públicos, enfrenta una grave contradicción que quizá sea una de las claves de la crisis fiscal del Estado de Bienestar moderno: a largo plazo, una buena política de inversión y localización empresarial, industrial y de servicios, que fomente el tejido y la actividad productivas, tiene más importancia para la determinación final del nivel de vida de una comunidad dada que una política de seguridad social basada en los clásicos mecanismos de subvención estatal. Entendida de esta manera, la política social conecta con la política económica general sin dejarse asimilar por ella, se aleja de la simple y clásica administración social basada en la protección subvencionada e incorpora en su área de problemas las consecuencias sociales de todas las formas de inversión ${ }^{6}$.

Es así como la globalización, si no pone fin al Estado de Bienestar Social, ha cambiado su estructura interna construyendo en prospectiva un estado neoliberal basado en políticas públicas tendientes a la privatización, al recorte del gasto público y a la desestatización; pues la inversión privada poco a poco sustituye y se apodera de los comandos políticos, que a nivel interno tenían los estados nación.

Rivera Urrutia, nos indica al respecto:

Cuando las actividades económicas producen efectos externos, ya sea costos o beneficios que no pueden ser atribuidos o cobrados a su productor, los resultados del mercado no serán eficientes. Ello es resultado de que dichas externalidades no son consideradas en los cálculos que sustentan las decisiones de producción y, en consecuencia, se tenderá a producir demasiado poco en el caso de la externalidades positivas y demasiado en el caso de las negativas en comparación con los niveles de producto socialmente eficientes. Un caso especial de las externalidades son los bienes públicos; esto es, bienes cuyo beneficios no son

\footnotetext{
5 Montoro, op. cit. nota 1, p. 18.

6 Idem. p. 15 . 
apropiables por individuos especificos ${ }^{7}$.

Bajo esa lógica el bienestar social se basa en el equilibrio corporativista global, cuyas conquistas son de libre mercado trasnacional a nivel mundial, la conformación de estados supranacionales y una competencia económica convertida en guerra mundial que ha y sigue construyendo políticas públicas genocidas a través de la llamada democracia y de los derechos humanos. En ese sentido, los Estados en vías de desarrollo no cuentan con la economía ni con los avances económicos básicos para hacer frente a una competencia económica transnacional, por ende, acuden al endeudamiento voluntario o forzado a través del Fondo Monetario Internacional, del Banco Mundial, con otros estados o corporaciones económicas trasnacionales, con el fin de estar en condiciones de competencia, aunque en niveles más bajos que los estados económicamente fuertes. Esto se traduce en el alineamiento de las democracias de los países pobres a las de los Estados económicamente dominantes.

\begin{abstract}
El Estado aparecía capturado por sus propias creaciones. ii) El rápido progreso tecnológico, la globalización de la economía y el aumento del valor de la información, implicaron que la situación competitiva de las firmas y países empezara a estar determinada por su habilidad para responder con rapidez a las tendencias tecnológicas y de los mercados. Sistemas regulatorios intrusos, agencias gubernamentales y regulaciones y normas opacas son fundamentalmente incompatibles con ambientes de mercado competitivos y abiertos. Como elementos relevantes en este giro en el caso de América Latina, cabe también mencionar que el grave endeudamiento externo que afectaba a la mayoría de las economías de la región hizo aparecer a la privatización como una fuente importante de recursos para hacer frente a dichas obligaciones ${ }^{8}$.
\end{abstract}

Lo anterior contribuye a la disminución de seguridad social para los ciudadanos, lo cual se traduce en violencia social y tipos delincuenciales a gran escala de terror institucionalizado o no. La corrupción y la impunidad aumentan, los sujetos sociales son los que directamente reciben la exclusión social: su importancia social ha disminuido al grado de que no son necesarios, hasta en tanto contribuyan de algún modo al sistema económico neoliberal. Nigel refiere: Las relaciones económicas entre los gobiernos se asemejan a una guerra: tratan de evitar la invasión de las importaciones y el capital extranjero y, al mismo tiempo, buscan invadir a los vecinos con exportaciones y capital 9 .

Por tanto, la globalización y los avances tecnológicos han contribuido a que los grandes flujos de capital se concentren en un corporativismo económico transnacional, trayendo como consecuencia la inevitable transformación del Estado de Bienestar Social al Estado Neoliberal; siendo este último el que administre las políticas públicas de corte neoliberal.

Con base en ello las políticas públicas se convierten en transnacionales y con pretensiones para formar bloques entre regiones o con base en el poderío económico de los países. De esta forma los Estados más pobres quedan excluidos o a merced de la grandes potencias económicas globales.

Por ende, el proteccionismo social deja de ser eficaz, eficiente y además funcional; las políticas públicas dentro de las administraciones tendrán como objetivo principal formar parte

\footnotetext{
7 Rivera Urrutia, op. cit. nota 3, p. 316.

8 Ídem. p. 320.

9 HARRIS, op. cit. nota 2, p. 173.
} 
de la dinámica económica neoliberal. Un ejemplo de ellos son las tendencias globales 2033 de España con respecto a sus políticas públicas, las cuales determina con base en su crecimiento económico:

En un mundo globalizado, en el que el proteccionismo es un recurso estéril, la competitividad es lo que determina el potencial de crecimiento de una economía. El anterior modelo productivo de España ha estado basado en buscar la competencia vía precio, es decir, haciendo las cosas más baratas. En el próximo ciclo debemos competir por valor añadido, haciendo las cosas mejor ${ }^{10}$.

Es importante vislumbrar que la especialización técnica y académica de los ciudadanos es de vital importancia, pues ello es fundamental para una economía competitiva, de tal suerte que los sujetos sociales que no cuenten con la especialización requerida pueden ser excluidos del aparato productivo. De hecho, en el neoliberalismo opera la recursividad con la especialización de las personas, es decir, nos encontramos en estados en los que la administración gubernamental, a través de sus políticas públicas, permite otorgar oportunidades a los especialistas, sea desde la perspectiva pública o privada; sin embargo, contrario sensu, excluye de la misma manera a todos aquellos que no pueden pagarla u obtenerla de algún modo. Heckman nos indica al respecto:

El aumento de lo imprevisible del comercio y la tecnología, la creciente apertura de las economías y el prejuicio ante la mano de obra no especializada en estas disciplinas actúan como fuerzas impulsoras del Estado de Bienestar, como un seguro contra el riesgo y como una protección contra los bajos salarios de la mano de obra no cualificada cuando se reduce su demanda en el mercado. A medida que las economías se abren, resulta mucho más difícil proteger a los trabajadores y a las empresas de los rigores del mercado. $Y$, de hecho, en economías menos protectoras, como las de EEUU y el Reino Unido, se observan aumentos sustanciales en desigualdad salarial y social, debido en parte a estas tendencias.

En el contexto actual ha surgido una prima para la flexibilidad y la capacidad de respuesta para las economías. Los altos niveles de especialización de la mano de obra y un entorno regulado que fomenta el cambio permiten que las economías se beneficien de nuevas oportunidades. Un sistema económico que estaba bien adaptado al entorno estable y predecible de los años 50 y 6o, en el que la mano de obra no especializada jugaba un papel importante se muestra ineficaz a principios del siglo XXI ${ }^{11}$.

Bajo esta tesitura, la problemática radica en el diseño de las políticas públicas para la inclusión de aquellos que no están especializados y además no son necesarios para el modo de producción neoliberal. Incluso la participación ciudadana, a efecto de que sea considerada eficaz, requiere de un nivel determinado de especialización, por lo menos tener las herramientas de conocimiento para acceder a la información pública a través de las tecnologías de la información y comunicación. En ese sentido, consideramos que las políticas públicas también se dirigen a la neutralización y/o a la eliminación de los sujetos sociales considerados como de desecho, toda vez que los mismos no aportan sistémicamente a la mecánica económica neoliberal, y al

\footnotetext{
${ }^{10}$ España en el mundo 2033 Cuatro escenarios para actuar ahora, Programa crecimiento inteligente, Javier Solana, [en línea], disponible en: www.pwc.es, p. 4.

${ }^{11}$ Heckman, James J. (2008), “La viabilidad del Estado de Bienestar”, Cuadernos de Pensamiento Político, Número 20, Octubre- diciembre, p. 136.
} 
contrario, se convierten en peligrosos, riesgosos y en lastres para la economía global, la cual es administrada desde una perspectiva trasnacional.

Por ello, la legitimación de los mecanismos en la administración pública han cambiado ideológicamente, al grado de que se considera que el Estado ya no es responsable de proveer satisfactores a los sujetos sociales, ello demuestra que éste último está provisto de políticas públicas neoliberales tendientes a la privatización y, por ende, a la eliminación de todos aquellos que no tienen acceso a los servicios que antes eran públicos y que, paulatinamente, se han privatizado ${ }^{12}$. Lo anterior se materializa como públicas respaldadas por el derecho ${ }^{13}$, no solo administrativo, sino de otros tipos como el derecho penal del enemigo; el cual, como última ratio, controla a través de la criminalización a todos aquellos que disientan en contra de las mismas.

Montero refiere al respecto al respecto:

Hasta ahora, en el modelo del Estado de Bienestar, el Estado ha asumido un papel principal (en la mayoría de las ocasiones monopolista, exclusivista) a la hora de producir bienestar, de proveer de los principales bienes y servicios relacionados con el bienestar que demanda cualquier sociedad moderna: salud, educación, seguridad en la renta de las personas envejecidas y enfermas, etc. Pero, por definición, estas necesidades, y las que se puedan ir añadiendo en los lógicos desarrollos sociales, no tienen porqué ser atendidas directa, total y absolutamente por el Estado. Incluso cabría poner en duda la legitimidad para que ocurra así ${ }^{14}$.

Lo cierto es que el Estado de Bienestar Social ha sido desmantelado en los países pobres que sufren la dinámica económica neoliberal, toda vez que las privatizaciones a causa de la inversión extranjera directa y como consecuencia de ello el recorte al gasto público, así como la no intervención estatal en la economía, han tenido como resultado la transformación del mismo

\footnotetext{
12 1. Descrédito de las Instituciones Públicas 2. El seguro popular 3. Mecanismos de aseguramientos de salud parciales 4. Separar las pensiones del IMSS y pasarlas a los bancos 5. Subrogación de Servicios de una Institución Pública de Salud a una Institución Privada 6. Las Instituciones Públicas pagan a Instituciones Privadas por determinados servicios de salud, tales como, resonancias magnéticas, etc. 7. Atención de la Salud en Farmacias de Genéricos (Privadas) 8. La asociación público-privada: El Estado transfiere a una empresa privada la responsabilidad de construir un hospital para que sea explotado por los privados y, a su vez, éstos devolverán la infraestructura después de 20, 30 o 40 años 9. Sustituir a las Instituciones Públicas por Instituciones Privadas. Lo anterior trae efectos positivos para los empresarios y capitales extranjeros, en donde la calidad de la atención dependerán de la cantidad que se pague por cierto tipo de servicio médico, dejando de ser la salud un derecho para convertirse en una mercancía. De hecho, el capital proveniente de los impuestos de los ciudadanos, son pagados a través del Estado hacia capitales privados. Lo anterior muestra una política pública neoliberal en materia de salud y que tiene graves consecuencias en la calidad de vida de las personas. Zafra, Xareni (2015), Laboratorio de Objetos de Aprendizaje, Universidad Autónoma Metropolitana, [en línea], disponible en: https://www.youtube.com/watch? $v=s k b \_1 k M 9 Z e A$, [consulta 9 de mayo del 2016, 17:39 hrs.].

${ }^{13}$ En el acuerdo ACDO.AS3.HCT.291117/275.P.DF y sus anexos, dictado por el H. Consejo Técnico del Instituto Mexicano del Seguro Social en la sesión ordinaria celebrada el día 27 de enero de dos mil dieciséis, relativo a la aprobación de los costos unitarios por Nivel de Atención Médica para el ejercicio fiscal 2016 se encuentran los precios al público para tener acceso a los Servicios Médicos que otorga el IMSS en caso de no ser derecho habiente, los cuales van desde $\$ 631.00$ (seiscientos pesos oo/10o M.N.) por consulta medico-familiar en unidades de atención de primer nivel, hasta \$34,232.00 (treinta y cuatro mil doscientos treinta dos pesos oo/100 M. N.) por día de terapia intensiva en unidades de atención de tercer nivel. H. Consejo Técnico DEL Instituto MeXiCano del Seguro Social (2017), “Acuerdo ACDO.AS3.HCT.291117/275.P.DF y sus anexos", Diario Oficial de la Federación, Secretaría de Gobernación, [en línea], disponible en: http://www.imss.gob.mx/sites/all/statics/pdf/ acuerdos/4165.pdf, [consulta 9 de mayo del 2016, 18:12 hrs.]. Sin embargo, el problema no termina ahí, pues con la falta de oportunidades para obtener un empleo legal, dada la especialización que éstos requieren gran parte de mexicanos quedan excluidos de este servicio de salud.

${ }^{14}$ Montoro, op. cit. nota 1, p. 12.
} 
en un Estado débil a merced de los intereses capitalistas-neoliberales, el cual no está preparado económicamente para hacer frente a las necesidades sociales y a la protección de los derechos humanos, sobre todo de la ciudadanía vulnerable y de aquellos que económicamente no aportan lo suficiente a la acumulación incesante de capital por la falta de especialización.

En este sentido ese margen de sujetos sociales se convierten en un lastre sistémico, el cual pretende ser controlado, neutralizado y hasta eliminado del mapa social a través de políticas públicas genocidas y de la aplicación del derecho penal del enemigo.

En un estado con tal dinámica, es normal que las política públicas se dirijan a la protección del capital, a la inversión extranjera directa, a la privatización incluso de las áreas estratégicas estatales, al recorte del gasto público sobre las áreas que no comparten la proliferación de los mecanismos neoliberales-globales y, sobre todo, a la eliminación de los sujetos sociales antidemocráticos. De esta forma la administración del estado se convierte en gendarme, en simple espectador-receptor de normas jurídicas que protegen políticas públicas transnacionales de corte neoliberal que son financiadas y dirigidas por el capital privado global; pero sobre todo, como ejecutor de las mismas en detrimento de los grupos sociales más frágiles.

\section{El Estado Necroneoliberal: La muerte y la violencia como ejes básicos de las políticas públicas}

Con el fin de analizar la eficacia, eficiencia y necesidades funcionales de la administración pública global y estatal, así como la materialización de la misma en políticas públicas, éstas deben ser estudiadas desde aspectos multidisciplinarios, tales como la economía, la política, y el derecho, entre otras. En este contexto, conforme al metodología de Mbembe utilizando como base de análisis la necropolítica ${ }^{15}$, Falomir Archambault propone como concepto de ésta:

Achille Mbembe sugiere que los regímenes politicos actuales obedecen al esquema de $<<$ hacer morir y dejar vivir $>$, y sitúa la aparición de esta nueva forma de control durante el período colonial, momento de gran desestructuración de los límites entre la vida y la muerte que propició el silenciamiento del cuerpo.

También se alude en Necropolítica a la cosificación del ser humano propia del capitalismo, que explora las formas mediante las cuales las fuerzas económicas e ideológicas del mundo moderno mercantilizan y reifican el cuerpo: se estudia de qué manera éste se convierte en una mercancía más, susceptible de ser desechada, contribuyendo a aniquilar la integridad moral de las poblaciones. Las personas ya no se conciben como seres irremplazables, inimitables e indivisibles, sino que son reducidas a un conjunto de fuerzas de producción fácilmente sustituibles.

Por tanto, la necropolítica podría definirse como una suerte de contrabiopoder ligado, sin duda, al concepto de necrocapitalismo, tal y como lo entiende Sayak Valencia en su ensayo "Capitalismo gore"; es decir, al capitalismo contemporáneo, que organiza sus formas de acumulación de capital como un fin absoluto que prevalece por encima de cualquier otra lógica o metanarrativa ${ }^{16}$.

Siguiendo a la autora, los sujetos sociales, en tanto ciudadanos, son diseñados físicamente y construidos ideológicamente de acuerdo al modo productivo neoliberal actual; en ese sentido,

\footnotetext{
${ }^{15}$ Este autor retoma la biopolítica de Michel Foucault para la creación de dicha categoría metodológica.

${ }^{16}$ Mвемe, Achille (2011), Necropolítica, Editorial Melusina, España, pp. 14-15. 
el neoliberalismo utiliza a la muerte y a la violencia como necesidad sistémica para la acumulación incesante de capital, siendo esta mecánica respaldada por el derecho; en virtud de ello la administración pública diseña, junto con sus políticas públicas, mecanismos para conminar a las dos primeras y así mantener el ejercicio del poder desde la perspectiva económica.

De hecho, Mbembe propone como tecnología política de control al necropoder, el cual es la base metodológica de su análisis: El necropoder es, más bien, una tecnología política diferenciada que tiene como fin la masacre poblacional, y, además, es una tecnología que desborda los límites de la estatalidad ${ }^{17}$.

Si aplicamos la tecnología política del necropoder indicada por Mbembe en las políticas económicas neoliberales, podemos señalar que el éxito de las mismas tienen como elementos básicos a la violencia, a la muerte y al terror propinado hacia los sujetos sociales. De hecho estos últimos elementos serían los más importantes para la funcionalidad de la constante acumulación incesante de capital. Es decir, la violencia genera capital, la muerte acumula fortunas y el terror es mecanismo esencial para el monopolio capitalista-neoliberal, y al mismo tiempo, excluye a todos aquellos que no son funcionales para el sistema. De igual forma conmina a una competencia económica a través de la necropolítica, lo cual se traduce en el control del capital, de la política y del derecho.

Por ello el terror, la muerte y la violencia que se implementan en el grosor social cumplen dos funciones: por un lado controlan a lo sujetos sociales conminándolos a determinada forma de actuar de acuerdo a las políticas neoliberales, y por el otro, permiten que se acumule capital incesantemente desde la perspectiva ilegal e ilegitima; sin embargo, el derecho y las políticas públicas crean mecanismos de recuperación de capital a efecto de legalizarlo para que se produzca a través de éstos elementos, tales como Convenciones de las Naciones Unidas, Tratados Internacionales, normas constitucionales, leyes secundarias, etc.

Andrea Ivana Gigena, citando a Mbembe, indica:

Pero veamos la trama del pensamiento de Achille Mbembe. En primer lugar, es necesario destacar que el "necropoder" está siempre e indisolublemente ligado al racismo: "Al fin y al cabo, mucha más que el pensamiento de clase (la ideología que define la historia como una lucha económica entre las clases), la raza ha sido la sombra omnipresente en el pensamiento y la práctica politica de occidente, sobre todo cuando se trata de imaginar a la inhumanidad de los extranjeros" 18 .

Esto implica que las técnicas de necropoder y las políticas públicas que tienen como uno de sus elementos de control a la necropolítica, hacen una distinción racista en cuanto a la administración de los sujetos en el mundo; es decir, la violencia y el terror no tienen el mismo grado de aplicación en todas las sociedades a nivel global; sino que existe un tipo de administración pública sistémico-global que clasifica a las sociedades y a los individuos decidiendo el tipo y nivel de terror que deba implementarse, entendiendo éste último como las tecnologías políticas necroneoliberales para la funcionalidad del sistema capitalista-neoliberal.

Por ello, en el mundo existen sociedades que actualmente cuentan con Estados fuertes de bienestar social, quienes económicamente están preparados para observar los derechos humanos y proteger a sus sujetos sociales, como es el caso de Alemania; pero también existen socie-

\footnotetext{
${ }^{17}$ Fuentes Díaz, Antonio (2012, coord.), Necropolitica, Violencia y excepción en América Latina, Benemérita Universidad Autónoma de Puebla, Instituto de Ciencias Sociales y Humanidades, México, p. 24.

${ }^{18}$ Íbidem, 17, p. 19.
} 
dades, como en algunos países en vías de desarrollo en los cuales el sistema económico neoliberal, a través de la privatización y del recorte al gasto público, no permite que el aparato estatal y la administración pública estén preparados económicamente para proteger a sus ciudadanos desde el derecho, por lo que no pueden otorgarles elementos de bienestar, y por el contrario, los sujetos improductivos se convierten en lastres sistémicos, por lo que las políticas públicas, la administración y la creación de normas jurídicas van dirigidas al genocidido de los mismos, restringiendo sus derechos humanos desde la perspectiva de la legalidad y legitimidad; y además, controlada a través de las técnicas del necropoder.

Este racismo que funciona como elemento biopolítico de control, Foucault lo describe de la siguiente forma:

Me parece que uno de los fenómenos fundamentales del siglo XIX es aquel mediante el cual el poder-por así decirlo-se hizo cargo de la vida. Es una toma de poder sobre el hombre en tanto ser viviente, es una suerte de estatalización de lo biológico. Creo que, para entender lo sucedido, podemos referirnos nuevamente a la teoría clásica de la soberanía, que nos sirvió como trasfondo y como marco de referencia para todos los análisis que hicimos sobre las guerras y sobre las razas. En la teoría clásica, el derecho de vida y muerte eran uno de los atributos fundamentales de la soberanía. Pero este derecho es, a nivel teórico, muy extraño. ¿Qué significa tener derecho de vida y muerte? Decir que el soberano tiene este derecho equivale en cierto sentido a decir que puede hacer morir o dejar vivir. En todo caso significa que la vida y la muerte no forman parte de esos fenómenos naturales, inmediatos, de algún modo originales o radicales, que parecen ser extraños en el campo del poder político ${ }^{19}$.

Mbembe interpreta el rascismo del cual habla Foucacult de la siguiente forma:

El racismo es, en términos foucaultianos, ante todo una tecnología que pretende permitir el ejercicio del biopoder, <<el viejo derecho soberano de matar $>>$. En la economía del biopoder, la función del racismo consiste en regular la distribución de la muerte y en hacer posibles las funciones mortíferas del Estado. Es, según afirma, <<la condición de aceptabilidad de la matanza>>.

Foucault plantea claramente que el derecho soberano de matar (droit de glaive) y los mecanismos del biopoder están inscritos en la forma en la que funcionan todos los Estados modernos; de hecho, pueden ser vistos como los elementos constitutivos del poder del Estado en la modernidad. Según Foucault el Estado Nazi ha sido el ejemplo más logrado de Estado que ejerce su derecho a matar. Este Estado, dice, ha gestionado, protegido y cultivado la vida coextesiva con el derecho soberano de matar. Por una extrapolación biológica del tema del enemigo político, al organizar la guerra contra sus adversarios y exponer también a sus propios ciudadanos a la guerra, el Estado Nazi se conceptúa como aquel que abrió la vida a una tremenda consolidación del derecho de matar, que culminó en el proyecto de la $<<$ solución final $>>$. De esta forma, se convirtió en el arquetipo de una formación de poder que combinaba las características del Estado racista, el Estado mortífero y el Estado suicida ${ }^{20}$.

El problema aquí radica en que el ejercicio del poder, con respecto al control biopolítico sobre la vida y la muerte de los ciudadanos, tiene una funcionalidad económico global de corte neoliberal, en la cual éstos son golpeados por la impunidad y la corrupción a causa de políticas públicas que no garantizan su vida, su salud, su libertad, entre otros. En donde las normas ju-

\footnotetext{
${ }^{19}$ Foucault, Michel (1996), Genealogía del Racismo, Argentina, Caronte Ensayos, p. 193.

${ }^{20}$ Mвeme, op. cit. nota 16, pp. 23-24. 
rídicas protegen al sistema económico neoliberal más que a la vida y bienestar social ${ }^{21}$. De esta forma el sistema sigue teniendo el control sobre la vida y la muerte, mediante instrumentos jurídicos y políticos que permiten la vulnerabilidad de los más débiles, y por el contrario, fortalece al ejercicio del poder económico.

En razón a lo anterior, Viviane Forrester indica:

Sin embargo, en este sistema sobrenada una pregunta esencial, jamás formulada: "Es necesario merecer el derecho de vivir?" una infima minoría, provista de poderes excepcionales, posee de oficio ese derecho. En cambio el resto de la humanidad, para "merecer" el derecho de vivir, debe demostrar que es "útil" para la sociedad, es decir, para aquello que la rige y la domina: la economía confundida más que nunca con los negocios, la economía de mercado. Para ella, "útil" significa casi siempre "rentable", es decir, que le dé ganancias a las ganancias.

Pero esa rentabilidad de los sujetos para ser incluidos en este sistema dista mucho de alquilar su fuerza de trabajo, más bien depende de su adaptación dentro de las tecnologías de inclusión en el neoliberalismo, tales como el consumismo.

Bajo esa lógica Zymunt Bauman nos señala:

El proceso de autoidentificación es algo buscado, y sus resultados son exhibidos con la ayuda de "marcas de pertenencia" visibles, por lo general asequibles en los comercios. En las "tribus posmodernas" (como Maseffoli prefiere llamar al "pelotón de la moda" de la sociedad del consumo), las "figuras emblemáticas" y sus marcas visibles (indicios que sugieren códigos de vestuario y/o de conducta) remplazan a los "tótems" de las tribus originales. Estar a la delantera luciendo los emblemas de las figuras emblemáticas del pelotón de la moda es la única receta confiable para asegurarse de que si el pelotón elegido supiera de la existencia del aspirante, seguramente le otorgaría el reconocimiento y la aceptación que tanto anhela. Y mantenerse a la delantera es el único modo de garantizar que ese reconocimiento de "pertenencia" dure tanto como se desea, vale decir, que lograr un acto único de admisión se solidifique y se convierta en un permiso de residencia con un plazo fijo pero renovable. En definitiva, "estar a la delantera" promete alguna certeza, alguna seguridad, alguna certeza de seguridad, precisamente el tipo de experiencia tan conspicua y dolorosamente ausente de la vida consumista, aún y cuando su objetivo no sea ni más ni menos el deseo de alcanzarlas ${ }^{22}$.

En este sentido, la administración y sus políticas públicas deben orientarse al mercado como una cultura de inclusión global, y el control de las masas se da desde la perspectiva de una competencia de mercado basada en la violencia, la muerte y el terror que causa la falta de oportunidades laborales, de salud, educativas, económicas, entre otras.

Gilles Lipovetsky nos dice con respecto al mercado como cultura global:

\footnotetext{
${ }^{21}$ Por ejemplo la Ley Federal para la Identificación y Prevención de Operaciones con Recursos de Procedencia Ilícita (Ley antilvado) tiene sus bases de criminalización en las llamadas actividades vulnerables, las cuales se encuentran descritas en el artículo 17 de dicha ley, cuya base económica va desde \$40,000.00 (cuarenta mil pesos oo/10o M.N.) Daniel Estulin indica al respecto:

La cantidad de dinero generada anualmente por el narcotráfico es probablemente unos de los secretos mejor guardados en el mundo; sin embargo, un experto en lavado de dinero que ostenta un alto cargo en la agencia del gobierno estadounidense encargada de vigilar las transacciones internacionales de capital me dijo una vez que <<en números redondos debe tratarse de una suma de unos 590 mil millones de euros anuales libres de impuestos $>$. De hecho el dinero de las drogas es hoy parte esencial del sistema bancario y financiero internacional porque aporta el dinero liquido necesario para realizar los pagos mensuales mínimos; además este dinero genera 6 veces más su valor. Estulin, Daniel (2012), Los secretos del Club Bilderberg, Bronce, España.

${ }^{22}$ Bauman, Zygmunt (2013), Vida de consumo, Fondo de Cultura Económica, México p. 116.
} 
La cultura-mundo designa el momento en que el capitalismo se ha extendido por todo el mundo, en el que el mercado se ha planetarizado, en que todas las naciones han tomado el camino de las privatizaciones y las desreglamentaciones económico-financieras. El capitalismo $<<q u e$ apareció en la civilización occidental y únicamente en ella $>>$ se ha universalizado. En todas partes reina ya el sistema del capitalismo globalizado y financierizado, un hipercapitalismo desbocado cuyo precio estamos pagando cruelmente. Como es lógico, la crisis mundial que atravesamos y que ha vuelto a dar al Estado un papel económico de primer orden comportará nuevas medidas reguladoras, hasta el extremo de que algunos han anunciado una inevitable ruptura con el paradigma del "turbocapitalismo" desmesurado y caótico ${ }^{23}$.

La tecnología del necropoder en el neoliberalismo opera en forma de una guerra económica de control global, en la cual se consideran enemigos políticos a todos aquellos que no se alinean con las políticas económicas neoliberales, cuyos resultados en ciertos casos merman la infraestructura de diversos grupos sociales.

Mbembe refiere al respecto:

En Kosovo, la degradación de las capacidades serbias tomó la forma de una guerra de infraestructuras que destruía puentes, redes de ferrocarril, autopistas, redes de comunicaciones, almacenes y depósitos de petróleo, instalaciones de calefacción, centrales eléctricas y equipamientos de tratamiento de aguas. Ya imaginamos que la ejecución de tales estrategias militares, sobre todo cuando se combinan con la imposición de sanciones, tiene como consecuencia la merma de todo el sistema de supervivencia del enemigo. Los daños duraderos en la vida civil son particularmente elocuentes. Por ejemplo, la destrucción del complejo petroquímico de Pancevo cerca de Belgrado durante la campaña de Kosovo $<<$ ha dejado tal nivel de toxicidad en los alrededores (cloruro de vinilo, amoníaco, mercurio, nafta y dioxina) que se recomendó a las mujeres embarazadas que recurrieran al aborto $y$, en toda la región, se aconsejó evitar los embarazos durante un período de dos años.

Por tanto, las guerras de la era de la globalización tienen como objetivo forzar al enemigo a la sumisión, sean cuales sean las consecuencias inmediatas, los efectos secundarios y los $<<$ daños colaterales $>>$ de las acciones militares ${ }^{24}$.

Por tanto, sería erróneo entender a la administración pública y a las políticas públicas domésticas alejadas de la globalización económica neoliberal y del control económico transnacional que tienen sobre los grupos sociales a través de la violencia, la muerte y el terror. Por tal motivo, las actuales políticas públicas distan mucho de resolver los problemas sociales, pues los individuos pasan a un segundo o hasta tercer plano de importancia con respecto a las dinámicas económicas de un mercado neoliberal globalizado.

En la actualidad todo se piensa en términos de competencia y de mercado (desde la clasifcación mundial de Shangai, hasta las universidades se han incluido en el orden de la competencia internacional), de rentabilidad y de éxito, de máximos resultados al menor coste,

\footnotetext{
${ }^{23}$ Lipovetsky, Gilles y Juvin, Hervé (2011), El occidente globalizado. Un debate sobre la cultura planetaria, Anagrama, España, p. 22.

${ }^{24}$ Mbeme, op. cit. nota 16, pp. 55-56.

CienCIA JURÍDICA. Departamento de Derecho. División de Derecho, Política y Gobierno, Universidad de Guanajuato - Año 7, No. 13, 2018
} 
de eficacia y beneficios. Mediante la universalización de este modelo imaginario-social el hipercapitalismo se presenta, paralelamente a su planetarización, como una cultura-mundo ${ }^{25}$.

Es así como las estructuras sistémicas de libre mercado procuran, con base en cualquier dinámica, y a través de actividades lícitas o ilícitas ${ }^{26}$, a acumular capital incesantemente a costa de la violencia, las muertes y el terror que pudiera generar en los sujetos sociales, convirtiéndolos a su vez en enemigos políticos y mermándolos en sus infraestructuras.

Jaime Osorio es muy puntual en este sentido:

La vocación del poder de apoderarse de la vida y someterla a sus atribuciones soberanas constituye un proceso antiguo. Sin embargo, la emergencia de fenómenos inéditos en esa vieja tendencia permite hablar de la constitución de algo nuevo, que se ha expresado en la noción de biopoder. Por lo tanto, el biopoder establece las particularidades en un contexto en donde el capital, su dinámica y despliegue, rigen el sentido del mundo y su organización ${ }^{27}$.

Es así como utilizando las categorías metodológicas de Foucault, Mbembe, Lipovetsky, Bauman, Perkins y Wallerstein ${ }^{28}$, podemos entender al necroneoliberalismo como aquella tecnología política utilizada por el ejercicio del poder económico neoliberal-global29, respaldada por el derecho, para controlar a los sujetos sociales a través de la violencia, la muerte y el terror;

25 Íbidem, p. 24.

${ }^{26}$ En este tema podemos citar como ejemplo de las actividades ilícitas que utilizan para controlar y dirigir el capital global hacia donde indica el ejercicio del poder económico. El libro de Jhon Perkins Confesiones de un Gánster Económico refiere que:

Los gángsteres económicos (Economic Hit Men, EHM) son profesionales generosamente pagados que estafan billones de dólares a países de todo el mundo. Canalizan el dinero del Banco Mundial, de la Agencia Internacional para el Desarrollo (USAID) y de otras organizaciones internacionales de $<<a y u d a\rangle>$ hacia las arcas de las grandes corporaciones y los bolsillos del puñado de familias ricas que controla los recursos naturales del planeta. Entre sus instrumentos figuran los dictámenes financieros fraudulentos, las elecciones amañadas, los sobornos, las extorsiones, las trampas sexuales y el asesinato. Ese juego es tan antiguo como los imperios, pero adquiere nuevas y terroríficas dimensiones en nuestra era de la globalización.

PERKINS, John (2005), Confesiones de un Gánster Económico. La cara oculta del imperialismo americano, Ediciones Urano, España, p. 9.

27 Osorio, Jaime (2012), Estado, biopoder, exclusión. Análisis desde la lógica del capital, Anthropos/Universidad Autónoma Metropolitana, México, p. 85.

${ }^{28}$ Nos encontramos en un sistema capitalista sólo cuando el sistema da prioridad a la incesante acumulación de capital. Frente al uso de tal definición, sólo el sistema-mundo moderno ha sido un sistema capitalista. La acumulación incesante en un concepto relativamente simple: significa que las personas y las compañías acumulan capital a fin de acumular más capital, es un proceso continuo. WAllerstein, Immanuel (2010), Análisis de sistemas-mundo. Una introducción, Siglo XXI, México, p. 40-41.

29

Bajo esta lógica John Perkins indica: "Tras la retórica patriotera y las llamadas a la acción, sin embargo, creí advertir una transformación mucho más sutil en la manera en que los intereses comerciales de Estados Unidos (y con ellos, la mayoría de las personas que trabajaban en las corporaciones estadounidenses) contemplaban el mundo. La marcha hacia el imperio global había cobrado realidad y buena parte del país participaba en ella. En los ánimos de todos influían en grado significativo dos conceptos íntimamente asociados: globalización y privatización.

En último análisis esto no sucedía sólo en Estados Unidos. El imperio global era justamente eso, global, pasando por encima de todas las fronteras. Las corporaciones que antes considerábamos estadounidenses, eran ahora internacionales en el pleno sentido, incluso jurídico de la palabra. Porque, al estar constituidas y registradas en muchos países, podían estudiar y elegir las legislaciones y las reglamentaciones que más le convinieran para conducir sus actividades. Un gran número de organizaciones y de acuerdos comerciales globalizadores les facilitaba la tarea todavía más. Las palabras democracia, socialismo y capitalismo caían casi en la obsolescencia. La corporatocracia prevalecía y se afirmaba cada vez más como la influencia principal cuando no única en la economía y la política del mundo. Perkins, John, op, cit. nota 26, p. 220. 
con el fin de acumular capital incesantemente (legal o ilegal), mediante la desestatización, privatización y recorte al gasto público, y al mismo tiempo eliminar, a través de cualquier medio, legítimo o ilegítimo, a todos aquellos que no son funcionales para la mecánica del libre mercado corporativista transnacional.

Entonces los sujetos sociales son disciplinados a través de la violencia, el terror y la muerte con el fin de que cumplan los objetivos de la mecánica económica neoliberal global. Por supuesto que ésto conmina a la corrupción política, jurídica y económica.

¿Qué hacer con todos aquellos que no puedan ser incluidos, por cuestiones de raza y de falta de oportunidades económico-sociales? La respuesta podría ser un genocidio silencioso a través de políticas públicas necroneoliberales respaldadas por el derecho y administradas por el ejercicio del poder económico.

Existen muchos ejemplos, algunos de ellos son el atentado de las torres gemelas del 2001 en Estados Unidos de América, lo que trajo como consecuencia la aceptación y promulgación en mes y medio de una de las normas transnacionales y extraterritoriales mas racistas de la historia de la humanidad: La Act Patriot, de la cual he realizado un análisis a detalle en mi obra titulada Delincuencia Organizada, lavado de dinero y terrorismo. El Derecho Penal del Enemigo y la restricción de los Derechos Humanos en el neoliberalismo jurídico ${ }^{30}$.

Otro ejemplo en México es la guerra contra el narco ${ }^{31}$ propuesta por el Presidente Felipe Calderón Hinojosa, la cual ha traído una ola de violencia, muerte y terror en el país; además de permitir la legitimación de normas penales de excepción, así como otorgarles facultades a los militares propias de un Estado de Excepción contenidas en el Código Penal Militar en el gobierno de Enrique Peña Nieto. Lo anterior es lógico, pues en un país donde el ordenamiento jurídico está deslegitimado socialmente, la fuerza básica de control se centra en la milicia.

\section{Conclusión}

El Estado de Bienestar social probablemente ha sido superado, la conquista de territorios se ha cambiado por la de mercados, cuyas técnicas políticas permiten el desarrollo del neoliberalismo. En este sentido, los sujetos sociales distan de ser importantes para el sistema, a menos de que cumplan con los lineamientos funcionales para la acumulación incesante de capital; bajo esta misma lógica actualmente son controlados a través de elementos biopolíticos de violencia, muerte y terror: tecnologías de poder necroneoliberal.

\section{Bibiografía}

Bauman, Zygmunt (2013), Vida de consumo, Fondo de Cultura Económica, México.

Estulin, Daniel (2012), Los secretos del Club Bilderberg, Bronce, España.

Foucault, Michel (1996), Genealogía del Racismo, Argentina, Caronte Ensayos.

\footnotetext{
30 Padilla Sanabria’ Lizbeth Xóchitl (2005), Delincuencia Organizada, Lavado de dinero y Terrorismo. El Derecho Penal del Enemigo y la restricción de Derechos Humanos, Flores Editor y Distribuidor, México.

${ }^{31}$ Este artículo da inicio a una serie que describe la violencia vinculada a los cárteles de la droga en México, sus conexiones globales en crecimiento y cómo afectan la vida cotidiana de la gente. Expansión, nota del editor, [en línea], disponible en: http://expansion.mx/nacional/2012/o1/2o/la-lucha-contra-el-narco-en-mexico-muertos-acambio-de-millones, [consulta el 15 de mayo del 2016, 20:57 hrs.].
} 
Fuentes Díaz, Antonio (2012, coord.), Necropolítica, Violencia y excepción en América Latina, Benemérita Universidad Autónoma de Puebla, Instituto de Ciencias Sociales y Humanidades, México.

Harris, Nigel (2006), "Globalización y tendencias en la gestión de las Ciudades", Gestión y Política Pública, volumen 15, Número 1, I Semestre.

Heckman, James J. (2008), "La viabilidad del Estado de Bienestar", Cuadernos de Pensamiento Político, Número 20, Octubre- diciembre.

Lipovetsky, Gilles y Juvin, Hervé (2011), El occidente globalizado. Un debate sobre la cultura planetaria, Anagrama, España.

Mbeme, Achille (2011), Necropolítica, Editorial Melusina, España.

Montoro, Romero, Ricardo (1997), "La Reforma del Estado de Bienestar: Derechos, deberes e igualdad de oportunidades", Revista Española de Investigaciones Sociológicas, número 79, Julio-septiembre.

Osorio, Jaime (2012), Estado, biopoder, exclusión. Análisis desde la lógica del capital, Anthropos/Universidad Autónoma Metropolitana, México.

Padilla Sanabria, Lizbeth Xóchitl (2005), Delincuencia Organizada, Lavado de dinero y Terrorismo. El Derecho Penal del Enemigo y la restricción de Derechos Humanos, Flores Editor y Distribuidor, México.Perkins, John (2005), Confesiones de un Gánster Económico. La cara oculta del imperialismo americano, Ediciones Urano, España.

Rivera Urrutia, Eugenio (2004), “Teorías de la regulación en la perspectiva de las políticas públicas", Gestión y Política Pública, volumen 13, número 2, II Semestre.

Wallerstein, Immanuel (2010), Análisis de sistemas-mundo. Una introducción, Siglo XXI, México.

\section{fuentes en internet}

España en el mundo 2033 Cuatro escenarios para actuar ahora, Programa crecimiento inteligente, Javier Solana, [en línea], disponible en: www.pwc.es, p. 4

Zafra, Xareni (2015), Laboratorio de Objetos de Aprendizaje, Universidad Autónoma Metropolitana, [en línea], disponible en: https://www.youtube.com/watch?v=skb_ıkMgZeA, [consulta 9 de mayo del 2016, 17:39 hrs.].

H. Consejo Técnico del Instituto Mexicano del Seguro Social (2017), “Acuerdo ACDO. AS3.HCT.291117/275.P.DF y sus anexos”, Diario Oficial de la Federación, Secretaría de Gobernación, [en línea], disponible en: http://www.imss.gob.mx/sites/all/statics/pdf/ acuerdos/4165.pdf, [consulta 9 de mayo del 2016, 18:12 hrs.]. 
Expansión [en línea], disponible en: http://expansion.mx/nacional/2012/01/20/la-lucha-contrael-narco-en-mexico-muertos-a-cambio-de-millones, [consulta el 15 de mayo del 2016, 20:57 hrs.]. 